\title{
Tongue ulcer in a patient with COVID-19: a case presentation
}

\author{
Mohammad Bashir Nejabi ${ }^{1}$, Noor Ahmad Shah Noor ${ }^{1}$, Nahid Raufi ${ }^{2,3}$, Mohammad Yasir Essar ${ }^{1,4}$, \\ Ehsanullah Ehsan ${ }^{5}$, Jaffer Shah ${ }^{4,6}$, Asghar Shah $^{7}$ and Arash Nemat ${ }^{8,9^{*}}$ (i)
}

\begin{abstract}
Background: The emergence of COVID-19 has devastated many parts of the world. From asymptomatic to symptomatic, the virus causes a wide spectrum of presentations. COVID-19 patients may present with oral manifestations. In Afghanistan, where COVID-19 has severely strained the health care system, much of the population lacks proper oral hygiene. This makes the oral cavity a perfect site for SARS-CoV-2 to manifest clinical signs.

Case presentation: A 62-year-old male was evaluated in the Dentistry Teaching Clinic of Kabul University of Medical Sciences for a painful erosive lesion on dorsal surface of his tongue. He also complained of fever, cough, and taste alteration. He was referred to Afghan Japan Hospital for COVID-19 testing and tested positive. He was followed on for the treatment of SARS-CoV2. After 2 weeks, the patient tested negative and returned to the dentistry clinic for follow-up. Although there were no other signs of COVID-19, the painful erosive lesion on his tongue persisted. Oral evaluation were performed and the patient was advised to practice good hygiene. After 10 days, we observed an asymptomatic geographic tongue without fever and myalgias and the lesion of dorsal surface of tongue improved from severe condition to moderate.
\end{abstract}

Conclusion: In conclusion, patients with suspected or confirmed SARS-CoV-2 should be screened for symptoms and physical findings in the oral mucosa To prevent such an outcome, awareness programs need to be implemented for the diagnosis and management of clinical symptoms among patients.

Keywords: COVID-19, SARS-CoV-2, Coronavirus, Oral manifestation, Tongue ulcer, Case report

\section{Background}

The novel coronavirus disease 2019 (COVID-19), a viral disease declared a pandemic by the World Health Organization (WHO) in March 2020, has caused a global health crisis affecting tens of millions of people with devastating health and economic consequences [1]. The disease is caused by the novel severe acute respiratory syndrome (SARS) coronavirus-2 (SARS-CoV-2), which causes viral pneumonia [2]. This virus creates widely varied clinical symptoms, from asymptomatic to mild, severe, and

\footnotetext{
${ }^{*}$ Correspondence: drarashnemat@yahoo.com

${ }^{8}$ Department of Cardiology, Nanfang Hospital, Southern Medical

University, Guangzhou, China

Full list of author information is available at the end of the article
}

critical [3]. Most cases present with mild symptoms, including dry cough, fever, sore throat, nasal congestion, and myalgias. Severe COVID-19 is characterized by severe pneumonia, and critical cases include respiratory failure, septic shock, and multiple organ failure. It has been reported that atypical manifestations could be in some cases the first or only manifestations of this disease [4]. Oral manifestations have been reported in multiple publications [5-7]. The palate and tongue were the most frequent locations, followed by gingiva and lips. Pain was reported by $75 \%$ of patients and $25 \%$ reported taste alterations [8-13]. Furthermore, the most frequently reported oral manifestations include ulcerative lesions, vesiculobullous/macular lesions, and acute sialadenitis of the parotid gland (parotitis)[14]. The etiology of oral lesions 
in patients with COVID-19 is still uncertain and seems to be multi-factorial. The appearance of such lesions may be related to the direct or indirect action of SARS-CoV-2 on the oral mucosa cells, hypersensitivity of drugs used in the treatment of COVID-19, downgrading of the general state of health of the patient due to the disease and long period of hospitalization [15]. There may be a link between COVID-19 and oral manifestations, but these signs may often go undetected due to a lack of intraoral examination during hospital admission [16]. Therefore, in this article, we aimed to report a case of oral manifestation in a COVID-19 diagnosed patient. This case builds on the findings of previous studies while highlighting the importance of full mouth examination to better understand the pathobiology of these oral alterations.

\section{Case presentation}

On 16th August 2020, a 62-year-old male presented to the Dentistry Teaching Clinic of Kabul University of Medical Sciences, due to a painful erosive ulcer on the dorsal surface of the tongue for one week. The patient reported that two weeks prior he had developed fever, cough, taste alterations, olfactory dysfunction, and chest tightness. He was referred to the local COVID-19 Hospital (Afghan-Japan Hospital) for the treatment of SARSCoV-2. His rRT-PCR test was positive. He was treated with azithromycin $500 \mathrm{mg}$ daily for one week and ceftriaxone $1 \mathrm{~g}$ twice a day for 3 days. After 2 weeks, a repeat COVID-19 test returned negative. When he came to the dentistry clinic, all of his symptoms had resolved except fora painful erosive lesion on the dorsal surface of his tongue. The patient had a history of controlled diabetes mellitus-type- 2 and moderate hypertension. He did not have a history of any oral diseases such as candidiasis, lichen planus, or HSV.

Physical examination revealed normal temperature (37C); blood pressure $135 / 88 \mathrm{mmHg}$, heart rate 80 ; respiratory rate 19 , and oxygen saturation $98 \%$. We observed a white geographic ulcer with irregular borders on the dorsum of the tongue.

Laboratory examinations showed normal differential leukocyte count (DLC) and total leukocyte count (TLC), C-reactive protein 22.4/L, and glucose $120 \mathrm{mg} / \mathrm{L}$. Computed tomography of lungs showed mild glass ground opacification bilaterally. Polymerase chain reaction (PCR) of a pharyngeal sample detected HSV-1 and he was treated with intravenous Acyclovir $5 \mathrm{mg} / \mathrm{kg}$ three times a day for 7 days with no effect on the oral lesions during the treatment.

For pain control of the ulcer, our dentist administered photobiomodulation therapy (PBMT) for 10 days. After 2 days of PBMT, the patient reported relief of symptoms and on the 11th day after PBMT treatment, the lesion partially resolved [17]. Besides the mentioned therapy, we recommended antibiotics (Azithromycin $500 \mathrm{mg}$ for 1 week), antiseptic agents (Chlorhexidine $0.12 \%$, alcoholfree mouth rinses, and $\mathrm{H} 2 \mathrm{O} 21 \%$ ), and antifungal agents (fluconazole $200 \mathrm{mg}$ tablets for 1 week) for the prevention of secondary infections. The patient was advised to avoid hot and spicy foods, but to drink plenty of fluids and eat a bland diet. We also advised the patient to practice good oral hygiene.

On August 30, 2020, he returned for a follow-up. During the examination, the patient had fewer clinical symptoms, and the size and mass of the lesion were changed to moderate compare to the severe form on the first examination. (Fig. 1).

\section{Discussion and conclusion}

Current research shows that the damage of coronavirus to respiratory and other organs could be related to the distribution of angiotensin-converting enzyme 2 (ACE2) receptors in the human system [18]. Therefore, cells with ACE2 receptor distribution may become host cells for the virus and further cause inflammatory reactions in related organs and tissues, such as the tongue, mucosa and salivary glands. In an analysis of 49 confirmed COVID patients, Zhong and colleagues found high expression of ACE2, and a high detection rate of SARS-CoV-2 RNA in saliva [19]. Moreover, existing evidence has not established an efficient and safe pharmacological agent against COVID-19 yet, and the potential ones are related to several adverse reactions, including oral lesions. Also, COVID-19 acute infection, along with associated therapeutic measures, could potentially contribute to adverse outcomes concerning oral health, likely leading to various opportunistic fungal infections, recurrent oral herpes simplex virus (HSV-1) infection, fixed drug eruptions, dysgeusia, xerostomia linked to decreased salivary flow, ulcerations and gingivitis as a result of the weak immune system and/or susceptible oral mucosa [20, 21]. Moreover, lack of oral hygiene, stress, immunosuppression, vasculitis and hyper-inflammatory response secondary to COVID-19 are some of the major predisposing factors for oral lesions in COVID-19 positive patients [22]. Similar oral conditions were presented by our patient and others have been previously reported $[9,23]$.

The existing literature on oral manifestations of COVID-19 provides support for our findings, treatment administered, and the ulcer outcome. A review of more than 170 COVID-19 positive cases found changes in tongue sensation and onset of tongue ulceration to be the most common symptoms [24]. The use of photobiomodulation therapy (PBMT) in managing oral lesions has been well documented [25]. Also, the specific use of PBMT as an effective treatment in COVID-19 patients 

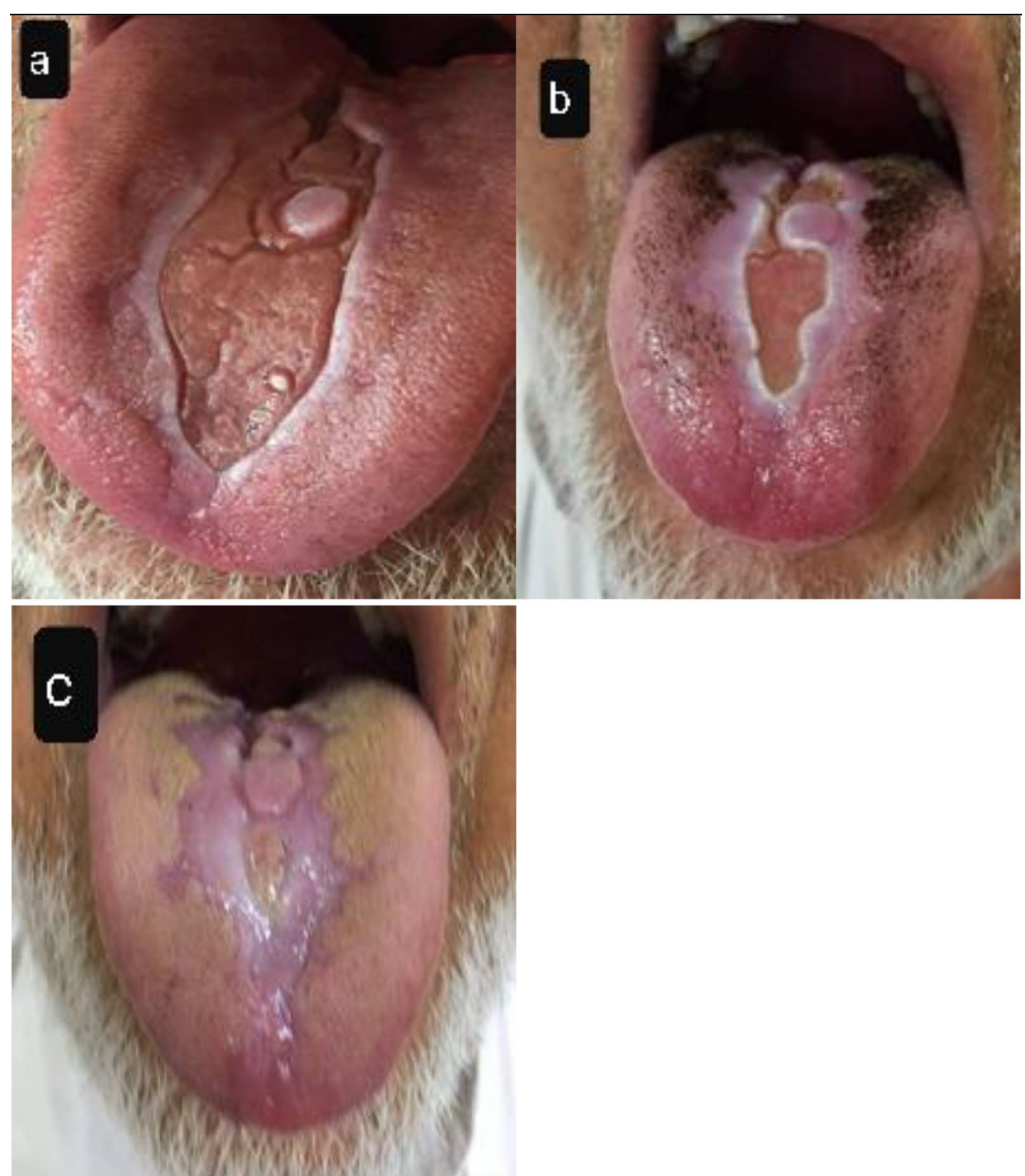

Fig. 1 a Fissured tongue with white scars after the COVID 19 recovery; b After 4 weeks the patient felt better and only he was complaining of burning on his tongue during the eating hot foods; $c 4$ weeks after the first examination

was reported by Soheilifar and colleagues [26]. Prior reporting has indicated improvements in lesion outcomes after treatment. Carreras-Presas reported three cases of intraoral lesions that were all treated between 3 and 10 days [27].

The occurrence of oral signs and symptoms should be considered in COVID-19 patients, including dysgeusia, petechiae, candidiasis, traumatic ulcers, HSV-1 infection, geographical tongue, thrush-like ulcers, among others. Santos and colleagues reported a case of oral mucosal lesions in a COVID-19 patient [28]. Other oral manifestations of the case included recurrent herpes simplex, candidiasis, and benign migratory glossitis. The researchers posit that some oral conditions may be a result of COVID-19 treatment and for this reason, oral health professionals should be included in the clinical care team. A review of 210 COVID-19 cases which reported prone positioning and mechanical ventilation devices in the ICU as resulting in oral mucocutaneous complications reached similar conclusions [29]. Hence, the importance of the clinical examination of the oral mucosa in patients with infectious diseases in the ICU 
should be emphasized, considering the need for support, pain control, and quality of life. Corchuelo and colleagues report the successful use of teleconsultation as facilitating the interdisciplinary approach for a patient asymptomatic COVID-19 presenting with Candida albicans, thrush, petechiae, and melanin hyperpigmentation at the gingival level [30].

Thorough oral examination, while practicing protective measures to avoid viral transmission, is important in addressing oral manifestations of COVID-19. To that end, Bordea and colleagues report a systematic review of guidelines to provide safe and efficacious oral care during the COVID-19 pandemic [31]. A retrospective study of 47 multisystem inflammatory syndromes in children (MIS-C) positive pediatric patients, who tested positive for COVID-19 infection, concluded that dental care providers play an important role in the early detection of MIS-C and in the identification of oral lesions in MIS-C patients [32]. They posit, furthermore, that MIS-C incidence is likely to increase as the number of COVID-19 positive cases continues to grow. All things considered, oral healthcare providers can play an important role in the detection and subsequent treatment of oral manifestations following COVID-19 infection.

In conclusion, we affirm that the problems that arise in the oral mucosa in patients with suspected or confirmed SARS-CoV-2 infection should be monitored during the pandemic, as demonstrated in our case of a dorsal tongue ulcer in a COVID-19-positive patient. To prevent such an outcome, awareness programs need to be implemented for the diagnosis and management of clinical symptoms among patients.

\section{Abbreviation}

PCR: Polymerase chain reaction.

\section{Acknowledgements}

Not applicable.

\section{Authors' contributions}

MBR and NAN performed the initial examination and collected clinical data, MYE provided the clinical dental care of the patient and have continued performing regular clinical follow-up. MBR supervised the clinical dental care of the patient. NR and EE were responsible for the literature search and wrote the paper. JS and AS revised and edited the manuscript and figures. AN provided comprehensive judgment and assisted in editing the final version of the manuscript. All authors read and approved the final manuscript.

\section{Funding}

Not applicable.

\section{Availability of data and materials}

The readers can acquire available data and materials in the current study by sending an email to dr.arashnemat@yahoo.com.

\section{Declarations}

Ethical approval and consent to participate

This work was carried in compliance with clinical ethical rules.

\section{Consent for publication}

Written informed consent was obtained from the patient for the publication of this case report and any accompanying images.

\section{Competing interests}

The authors declare that they have no competing interests.

\section{Author details}

${ }^{1}$ Faculty of Dentistry, Kabul University of Medical Sciences, Kabul, Afghanistan. ${ }^{2}$ Department of Dermatology, Kabul University of Medical Sciences, Kabul, Afghanistan. ${ }^{3}$ Department of Dermatology, Guangdong Provincial Dermatology Hospital, Southern Medical University, Guangzhou, China. ${ }^{4}$ Medical Research Center, Kateb University, Kabul, Afghanistan. ${ }^{5}$ Department of Dermatology, Alberoni University, Kapisa, Afghanistan. ${ }^{6}$ Drexel University College of Medicine, Philadelphia, PA, USA. ${ }^{7}$ Division of Biology and Medicine, Brown University, Providence, RI, USA. ${ }^{8}$ Department of Cardiology, Nanfang Hospital, Southern Medical University, Guangzhou, China. ${ }^{9}$ Department of Microbiology, Kabul University of Medical Sciences, University Road, Ali Abad, Jamal Mina, 3rd District, Kabul 1001, Afghanistan.

Received: 10 March 2021 Accepted: 14 May 2021

Published online: 20 May 2021

\section{References}

1. Melo P, Barbosa JM, Jardim L, Carrilho E, Portugal J. COVID-19 management in clinical dental care. Part I: epidemiology, public health implications, and risk assessment. Int Dent J. 2021. https://doi.org/10.1016/j. identi.2021.01.0157.

2. Lai C-C, Shih T-P, Ko W-C, Tang H-J, Hsueh P-R. Severe acute respiratory syndrome coronavirus 2 (SARS-CoV-2) and coronavirus disease-2019 (COVID-19): the epidemic and the challenges. Int J Antimicrob Agents. 2020:55(3):105924.

3. Wu Z, McGoogan JM. Characteristics of and important lessons from the coronavirus disease 2019 (COVID-19) outbreak in China: summary of a report of 72314 cases from the Chinese Center for Disease Control and Prevention. JAMA. 2020;323(13):1239-42.

4. Daruich A, Martin D, Bremond-Gignac D. Ocular manifestation as first sign of coronavirus disease 2019 (COVID-19): interest of telemedicine during the pandemic context. J Fr Ophtalmol. 2020;43(5):389-91.

5. Brandão TB, Gueiros LA, Melo TS, Prado-Ribeiro AC, Nesrallah ACFA, Prado GVB, Santos-Silva AR, Migliorati CA. Oral lesions in patients with SARSCoV-2 infection: could the oral cavity be a target organ? Oral Surg Oral Med Oral Pathol Oral Radiol. 2021:131(2):e45-51.

6. Díaz Rodríguez M, Jimenez Romera A, Villarroel M. Oral manifestations associated with COVID-19. Oral Dis. 2020. https://doi.org/10.1111/odi. 13555.

7. Capocasale G, Nocini R, Faccioni P, Donadello D, Bertossi D, Albanese M, Zotti F. How to deal with coronavirus disease 2019: a comprehensive narrative review about oral involvement of the disease. Clin Exp Dent Res. 2020;7:101-8.

8. Ansari R, Gheitani M, Heidari F, Heidari F. Oral cavity lesions as a manifestation of the novel virus (COVID-19). Oral Dis. 2020;27:771-2.

9. Chaux-Bodard A-G, Deneuve S, Desoutter A. Oral manifestation of Covid19 as an inaugural symptom? J Oral Med Oral Surg. 2020;26(2):18.

10. Ciccarese G, Drago F, Boatti M, Porro A, Muzic SI, Parodi A. Oral erosions and petechiae during SARS-CoV-2 infection. J Med Virol. 2021;93(1):129-32.

11. Cebeci Kahraman F, Çaşkurlu H. Mucosal involvement in a COVID-19-positive patient: a case report. Dermatol Ther. 2020;33(4):e13797.

12. Martín Carreras-Presas C, Amaro Sánchez J, López-Sánchez AF, Jané-Salas E, Somacarrera Pérez ML. Oral vesiculobullous lesions associated with SARS-CoV-2 infection. Oral Dis. 2020;27:710-2. 
13. Soares CD, de Carvalho RA, de Carvalho KA, de Carvalho MGF, de Almeida OP. Letter to Editor: oral lesions in a patient with Covid-19. Medicina oral, patologia oral y cirugia bucal. 2020;25(4):e563.

14. Halboub E, Al-Maweri SA, Alanazi RH, Qaid NM, Abdulrab S. Orofacial manifestations of COVID-19: a brief review of the published literature. Braz Oral Res. 2020. https://doi.org/10.1590/1807-3107bor-2020.vol34. 0124.

15. De Sousa FACG, Paradella TC. Considerations on oral manifestations of COVID-19. J Med Virol. 2021;93(2):667-8.

16. Sinadinos A, Shelswell J. Oral ulceration and blistering in patients with COVID-19. Evid Based Dent. 2020;21(2):49-49.

17. Bardellini E, Veneri F, Amadori F, Conti G, Majorana A. Photobiomodulation therapy for the management of recurrent aphthous stomatitis in children: clinical effectiveness and parental satisfaction. Medicina oral, patologia oral y cirugia bucal. 2020;25(4):e549-53.

18. Devaux CA, Rolain J-M, Raoult D. ACE2 receptor polymorphism: Susceptibility to SARS-CoV-2, hypertension, multi-organ failure, and COVID-19 disease outcome. J Microbiol Immunol Infect. 2020;53:425-35.

19. Zhong F, Liang $Y, X u$ J, et al. Continuously high detection sensitivity of saliva, viral shedding in salivary glands and high viral load in patients with COVID-19. 2020. https://doi.org/10.2139/ssrn.3576869.

20. Silva LN, de Mello TP, de Souza RL, Branquinha MH, Roudbary M, Dos Santos ALS. Fungal infections in COVID-19-positive patients: a lack of optimal treatment options. Curr Top Med Chem. 2020;20(22):1951-7.

21. Busani S, Bedini A, Biagioni E, Serio L, Tonelli R, Meschiari M, Franceschini E, Guaraldi G, Cossarizza A, Clini E. Two fatal cases of acute liver failure due to HSV-1 infection in COVID-19 patients following immunomodulatory therapies. Clin Infect Dis. 2020. https://doi.org/10.1093/cid/ciaa1246.

22. Iranmanesh B, Khalili M, Amiri R, Zartab H, Aflatoonian M. Oral manifestations of COVID-19 disease: a review article. Dermatol Ther. 2021;34(1):e14578.

23. Vieira AR. Oral manifestations in coronavirus disease 2019 (COVID-19). Oral Dis. 2020;27:770.
24. Zarch RE, Hosseinzadeh P. COVID-19 from the perspective of dentists: a case report and brief review of more than 170 cases. Dermatol Ther. 2021;34(1):e14717.

25. Hanna R, Dalvi S, Benedicenti S, Amaroli A, Sălăgean T, Pop ID, Todea D, Bordea IR. Photobiomodulation therapy in oral mucositis and potentially malignant oral lesions: a therapy towards the future. Cancers. 2020;12(7):1949.

26. Soheilifar S, Fathi H, Naghdi N. Photobiomodulation therapy as a high potential treatment modality for COVID-19. Lasers Med Sci. 2020. https:// doi.org/10.1007/s10103-020-03206-9.

27. López-Sánchez A, Jané-Salas E, ML SP: Oral vesiculobullous lesions associated with SARS-CoV-2 infection. Oral Diseases 2020.

28. Dos Santos JA, Normando AGC, da Silva RLC, De Paula RM, Cembranel AC, Santos-Silva AR, Guerra ENS. Oral mucosal lesions in a COVID-19 patient: new signs or secondary manifestations? Int J Infect Dis. 2020;97:326-8.

29. Hocková B, Riad A, Valky J, Šulajová Z, Stebel A, Slávik R, Bečková Z, Pokorná A, Klugarová J, Klugar M. Oral complications of ICU patients with COVID-19: case-series and review of two hundred ten cases. J Clin Med. 2021;10(4):581.

30. Corchuelo J, Ulloa FC. Oral manifestations in a patient with a history of asymptomatic COVID-19: case report. Int J Infect Dis. 2020;100:154-7.

31. Bordea IR, Candrea S, Sălăgean T, Pop ID, Lucaciu O, llea A, Manole M, Băbțan A-M, Sirbu A, Hanna R. Impact of COVID-19 pandemic on healthcare professionals and oral care operational services: a systemic review. Risk Manag Healthc Policy. 2021;14:453.

32. Halepas S, Lee KC, Myers A, Yoon RK, Chung W, Peters SM. Oral manifestations of COVID-19 related multi-system inflammatory syndrome in children: a review of 47 pediatric patients. J Am Dent Assoc. 2020;152:202-8.

\section{Publisher's Note}

Springer Nature remains neutral with regard to jurisdictional claims in published maps and institutional affiliations.
Ready to submit your research? Choose BMC and benefit from:

- fast, convenient online submission

- thorough peer review by experienced researchers in your field

- rapid publication on acceptance

- support for research data, including large and complex data types

- gold Open Access which fosters wider collaboration and increased citations

- maximum visibility for your research: over $100 \mathrm{M}$ website views per year

At BMC, research is always in progress.

Learn more biomedcentral.com/submissions 